\title{
ELEMENTOS MÍTICOS GRECOLATINOS EN ESTELAS $Y$ OTROS POEMAS DE MANUEL VERDUGO
}

\author{
Germán Santana Henríquez - Sara Lázaro García \\ Universidad de Las Palmas de Gran Canaria \\ german.santanahenriquez@ulpgc.es - sara.garcia102@alu.ulpgc.es
}

\begin{abstract}
RESUMEN
En el presente trabajo pasamos revista a los elementos míticos grecolatinos presentes en la obra Estelas y otros poemas del poeta filipino-canario Manuel Verdugo Bartlett, un autor parnasiano cuya producción registra un fuerte influjo de la cultura de Grecia y Roma, especialmente en sus momentos más decadentes.

Palabras Clave: Tradición Clásica, Mitología grecorromana, Estelas y otros poemas, Manuel Verdugo.
\end{abstract}

\section{ABSTRACT}

"Mythical Greco-Roman elements in Estelas and other poems by Manuel Verdugo». In the present work we review the mythical Greco-Roman elements present in the work Estelas and other poems of the Philippine-Canary poet Manuel Verdugo Bartlett, a Parnassian author whose production registers a strong influence of the culture of Greece and Rome, especially in its moments more Decadent.

KeY WORDS: Classical Tradition, Greek-Roman Mythology, Estelas y otros poemas, Manuel Verdugo.

Para el presente trabajo, nos centraremos en la obra Estelas y otros poemas de Manuel Verdugo, con estudio introductorio de Lázaro Santana, perteneciente a la Biblioteca Básica Canaria (1989). El mundo clásico presente en autores canarios se ha abordado hasta la fecha solo esporádicamente. Por ello, nos entusiasma presentar este trabajo como una muestra de las relaciones existentes entre la cultura clásica y la literatura canaria, para reflejar la presencia de la tradición clásica y elementos míticos grecolatinos en la obra del autor canario Manuel Verdugo Barlett. La antología de Lázaro Santana presenta una selección de la obra poética de Manuel Verdugo que se nutre principalmente de su obra más lograda, Estelas, que se ofrece en su integridad. Un poemario donde Verdugo muestra ampliamente su predilección por recrear figuras y ambientes clásicos, griegos y romanos. De las obras poéticas de Verdugo: Hojas, Huellas en el páramo y Burbujas, Santana incluye una breve selección. 
Del primero se han salvado los poemas que aparecen anunciar el tono y los temas de Estelas, y del segundo, aquellos que intentan prolongarlos. [...] Burbujas es un libro de ingenio más que de poesía. Aun así, y casi como curiosidad humorística, se han seleccionado varios de sus epigramas. [...] Verdugo fue siempre un poeta adicto al uso de la ironía y la sátira (1989: 21).

Resulta atrayente señalar que Lázaro Santana en su prólogo detecta una característica en la poesía de Verdugo que, a su entender, no ha sido mencionada por los críticos que se han ocupado de la obra poética de Manuel Verdugo y que él define como "la condición uranista de Verdugo". Sostiene que ya en su primer libro, Hojas" , "aparece tímidamente" ese carácter uranista y señala los poemas "A Urania" y "Champagne" (1989: 16) como ejemplos que dejan entrever esa condición; aunque será en Estelas,

donde la condición uranista de Verdugo se muestra más ampliamente [...] Verdugo anima en sus versos a algunos notorios homosexuales de la época (Antinoo, Heliogábalo) produciendo un poema de carácter reflexivo o narrativo en tercera persona, pero situándose él mismo muy próximo a la acción — de la que es cómplice evidentemente- (1989: 17).

Santana encuentra ciertas coincidencias entre la poesía de Verdugo y la de Cavafis, y un precedente de la de Luis Cernuda; esta opinión se basa en el común gusto de los tres por el mundo clásico decadente, su unánime recurrencia a la "extranjería de la belleza” y la actitud negativa frente al matrimonio (1989: 18-19).

Quizás no es arriesgado ver en esa disposición amorosa de Verdugo su posterior retraimiento de la poesía. El no poder expresar de una manera abierta y sincera sus sentimientos acaso produjo en él una voluntaria —o involuntaria - sequedad creadora (1989: 20).

María Rosa Alonso, en su monumental estudio de la obra poética de Manuel Verdugo $^{2}$, diferencia varios aspectos a los que hace referencia el autor en su obra Estelas a la que ella llama "el libro de la plenitud" y que "tiene la unidad y el rango de una biografía o, si se quiere, de una autobiografía". M. Rosa hace una clasificación que nos parece relevante e interesante para agrupar a grandes rasgos Estelas y que enumeramos a continuación (2009: 50):

${ }^{1}$ Manuel Verdugo Barlett (1905), Hojas, Madrid.

${ }^{2}$ María Rosa Alonso (2009): Manuel Verdugo y su obra poética, Islas Canarias, editado por la Sociedad Estatal de Conmemoraciones Culturales y Viceconsejería de Cultura del Gobierno de Canarias. 
1) Actitud ante la vida. Serán las composiciones que afectan a la manera personal y subjetiva que tiene Verdugo de entender la vida, de vivirla y de enquistarse en la misma.

2) El pasado. Composiciones en que Verdugo se sitúa ante el tiempo y valora su dimensión de pasado, herencia del alma romántica.

3) El amor. Sus experiencias amorosas; qué es para él el amor, cómo lo ha sentido $\mathrm{y}$ ha vivido.

4) La fe y el destino. Versos que aluden a los hondos problemas de la fe y el destino, sentidos y dramatizados en primera persona.

5) Las ideas estéticas. Composiciones referidas a su concepción estética.

6) Visiones y paisajes. Poemas relacionados con sus visiones del mundo y paisajes de la naturaleza.

7) Los temas clásicos. Grupo que contiene las composiciones que nos dan sus preferencias por el tema clásico y que comprenden tres apartados: a) los mitos, b) asuntos griegos y c) asuntos romanos.

8) La estampa, el retrato, la meditación y la ironía. Las estampas vienen a ser algo similar a lo que en pintura se llama cuadros de género. Añadiremos a este mismo grupo las composiciones que llamamos retratos (porque son verdaderamente retratos individuales); las que suponen una meditación del poeta y las que destacan como nota de relieve la ironía.

9) Las semblanzas y las poesías de circunstancias. Las semblanzas poéticas agrupan composiciones que afectan a su impresión de los hombres célebres.

\section{MANUEL VERDUGO. VIDA Y OBRA}

Manuel Verdugo destacó durante las primeras décadas del siglo pasado, especialmente, en poesía con su obra Estelas. Su nombre figura en las principales Antologias, Historias y otras monografías de literatura canaria, como por ejemplo, las conocidas selecciones de S. Padrón Acosta ${ }^{3}$, D. Pérez Minik ${ }^{4}$, J. Quintana ${ }^{5}$, A. Sánchez Robayna $^{6}$, A. Valbuena Prat ${ }^{7}$ y las de Joaquín Artiles e Ignacio Quintana ${ }^{8}$. Pero, será M. Rosa Alonso quien le dedique un amplio estudio en el que analiza con pormenor su obra poética". Sin embargo, "un poeta como Manuel Verdugo, la mayor parte de

${ }^{3}$ Cien sonetos de autores canarios, Santa Cruz de Tenerife, 1950.

${ }^{4}$ Antología de la poesía canaria, Santa Cruz de Tenerife, 1952.

596 poetas de las Islas Canarias, Bilbao, comunicación literaria de autores, 1970.

${ }^{6}$ Museo Atlántico. Antología de la poesía canaria, Santa Cruz de Tenerife, 1983.

${ }^{7}$ Historia de la poesía canaria, tomo I, Barcelona, Universidad de Barcelona, 1937.

${ }^{8}$ Historia de la literatura canaria, Las Palmas, 1978; J. Artiles, Historia de la literatura canaria, Las Palmas, 1979.

'María Rosa Alonso, Manuel Verdugo y su obra poética, 2009, Islas Canarias, editado por la Sociedad Estatal de Conmemoraciones Culturales y Viceconsejería de Cultura del Gobierno de Canarias. 
cuya obra, muy celebrada en su tiempo, resulta hoy sorprendentemente endeble" dice por su parte A. Sánchez Robayna (1983: 29).

La obra de Manuel Verdugo ha sido, en líneas generales, muy elogiada. Ejemplo de la grandeza de la poesía de Verdugo se encuentra en los testimonios de nuestros críticos. Así, S. Padrón nos dice

es obra de maravilloso poeta, de hombre de vasta cultura. Es una obra original acusada, producto de cerebro creador [...]. Lo mejor de la obra poética de Verdugo está en su libro Estelas, que coloca a Verdugo entre los mejores poetas españoles contemporáneos. (1966: 318-319).

Considerado por Pérez Minik "figura sobresaliente de la poesía de las islas" (2004: 146); también José Quintana en su obra 96 poetas de las Islas Canarias (siglo XX) considera que "los dos más grandes poetas isleños que fundamentaron la poesía en Canarias" son Manuel Verdugo y Tomás Morales. Por otra parte, Valbuena Prat define a Verdugo como "un poderoso arquitecto de versos e ideas" (1937: 108). A la poesía de Verdugo se la ha calificado de culta, reflexiva, elegante, ingeniosa y brillante. Su maestría en la forma, su acierto en la expresión, la hondura de pensamiento y la belleza de forma y contenido fueron precisamente las cualidades que destacó Manuel Machado en 1946, en una reseña de sus poemas. M. Martínez Hernández, en un estudio dedicado a nuestro autor, nos recopila elogiosos epítetos que le dedicaron grandes personalidades poéticas de su época como "gran poeta (J. Benavente), maestro poeta (A. Machado), altísimo poeta (T. Morales), etc.” (2001: 237). Hoy, por el contrario, no perdura la misma valoración sobre su obra.

Desde el punto de vista de su personalidad, en cambio, los elogios no han sido tan elocuentes. Se le ha caracterizado como una persona áspera y arisca, retraída y solitaria, un hombre agresivo, "dotado de un espíritu crítico de grandes vuelos, que no dejaba pasar nada" dice L. Álvarez Cruz. Este talante hipercrítico le llevó a sostener en más de una ocasión polémicas literarias. Famosas fueron, entre otras, las sostenidas con Salvador Rueda y con Agustín Espinosa, que habían sido comandados por Antonio Valbuena, a su llegada a la Universidad de La Laguna, en 1926, formándose incluso dos grupos oponentes en cuestiones literario-artísticas con los nombres de "valbuenistas" y "verduguistas". Pero, por otra parte, también se ha resaltado su tremenda humanidad, cualidad de gran valor para él con la que introduce su libro Estelas: "A un artista sólo se le puede exigir que el fondo de sus obras sea esencialmente humano" (1989: 43).

A pesar de su polémica con alguno de los representantes del modernismo, el propio poeta se confiesa modernista, y así nos lo cuenta en la entrevista que le realizó Luis Alejandro ${ }^{10}$ :

${ }^{10} C f$. Luis Alejandro, "Un artífice del verso: Manuel Verdugo, parnasiano y satírico", en $L a$ Tarde, página 5, el día 16 de septiembre de 1946, Tenerife. 
Yo rindo culto absoluto a la forma. La forma pura. Es insustituible. Siento verdadera adoración por la forma. Aunque algunos no lo crean [...] Soy un parnasiano convencido. Existen poetas que lo consideran algo anticuado. Yo me enorgullezco de ello (Verdugo, 1946).

M. Rosa Alonso lo define como "un caso curioso de autodidactismo estético, su firme postura literaria ante la escuela modernista y ante todo lo que signifique creación poética a base de la alteración de la forma” (2009: 23). Pero la filóloga tinerfeña nos deja claro en su obra En unas líneas que "Verdugo puede ser considerado como un tardío epígono parnasiano; pero nótese que hay en sus temas clásicos, no aquella serenidad despersonalizada de los parnasianos, sino evocación sentimental melancólica, muy modernista y finisecular" (2010: 69) y nos deja como ejemplo su poema titulado El mito de las Hespérides (1945: 18). Verdugo, que ha trabajado muy bien la forma poética, confiesa que no hay nada más complejo que la personalidad literaria de un poeta y que esta llega con la línea estética trabajada con el curso de los años. Además, critica a quienes creen tener esa personalidad literaria de la que habla sin habérsela trabajado ${ }^{11}$.

Desde el punto de vista estético, a Manuel Verdugo se le ha caracterizado como un típico ejemplo de autodidactismo de fin de siglo, levemente romántico, de elegante melancolía y tedio finisecular, que se mueve dentro de los cánones del Parnasianismo, el Modernismo y la Generación del 98, los tres grandes movimientos literarios de fines del siglo XIX y primeras décadas del XX. De ahí que la nómina de las personas que contribuyeron a su formación, o con las que mantuvo alguna amistad, sea realmente impresionante: Bécquer, Campoamor, Núñez de Arce, Gabriel y Galán, Bartrina, E. Funes, Mario de Cavia, A. Nervo, J. Dicenta, Villaespesa, J. Benavente, Valle-Inclán, Santos Chocano, Tomás Morales, los hermanos Machado y R. Darío, entre otros. M. Rosa Alonso lo sintetiza de la siguiente manera:

En, efecto, de excelente cultura y formación europea, viajero en su juventud, prendado de Italia, admirador de Hugo, Baudelaire y Verlaine, era el menos provinciano de todos y poco o nada sensiblero. Elegante y sobrio en la expresión, de buen oído rítmico, heredó de Bécquer una fina melancolía, que el positivismo irónico de Campoamor y de Bartrina le hizo diluir en pinceladas encubiertas por una impasibilidad de mármol más o menos frío, aprendida con los parnasianos y adobada con precauciones por el condimento modernista (2009: 130-131).

${ }_{11}$ "Tal personalidad está constituida por infinidad de influencias de otros poetas a los cuales un alma sensitiva no puede sustraerse. Esas causas externas, a la larga, llegarán a cristalizar, y forman el molde de donde surge el extraño yo, heterogéneo e indivisible. El afán prematuro de singularizarse, el vanidoso y huero deseo de originalidad, ha convertido a muchas liras en grotescos guitarrillos destemplados [...] Muchos de los que padecen la ridícula manía de ser inconfundible, concluyen por conseguirlo a fuerza desafinar." (Verdugo, 1915: 12). 
Uno de los aspectos que más llama la atención es el de su vasta preparación cultural. Dominaba varios idiomas ${ }^{12}$, era competente en varias disciplinas de su época ${ }^{13}$ y tenía un gran conocimiento de la cultura greco-latina de la que está impregnada su obra, considerado "un ejemplo importante de contribución de la cultura y civilización clásica” (2001: 253). Esta cultura eminentemente europea fue adquirida durante sus viajes por Europa y se hace evidente por la relación de algunos autores extranjeros expresamente citados a lo largo de su producción: O. Wilde, V. Hugo, Zola, Baudelaire, P. Hervieu, Goethe, Th. Mann, Pico de la Mirandola, D’Annunzio, Rossetti, Marineti, etc. No debemos olvidar que Verdugo fue también pintor y llegó a realizar alguna exposición.

Como dice M. Rosa Alonso con ocasión de su muerte:

Era el poeta europeo pasado por el inefable París impresionista de fin de siglo [...] Gran señor del viejo cosmopolitismo modernista hizo juventud en Europa y en Madrid con finas gentes de letras. En sus maneras y en su léxico tenía el cuño del hombre de estilo europeo (2008: 69).

Su cosmopolitismo es lo que lo distingue sobre todo de sus otros colegas de la denominada "Escuela poética regional" lagunera. De hecho Valbuena Prat, lo clasifica como "uno de los representantes más típicos del cosmopolitismo" (1937: 107).

Manuel Verdugo Barlett nació el 31 de diciembre de 1877 en Manila (Filipinas $)^{14}$, ciudad en la que estaba destinado su padre como general de artillería ${ }^{15}$, siendo el cuarto de siete hermanos. En 1880 pasó a Madrid con los suyos por haber sido destinado su padre a la capital de España. A los seis años perdió a su madre ${ }^{16}(1883)$ y en diciembre de ese año regresa con la familia a Manila, donde había sido destinado su padre de nuevo. En aquella ciudad permaneció el futuro poeta hasta 1892, que torna a Madrid por nuevo traslado de don Federico, su padre; Manuel Verdugo tenía catorce años. A los dieciséis (1894), ingresa en la Academia de Artillería en Segovia de la que sale a los veintiún años con el grado de primer teniente. Durante

12 "Llegando a publicar en la prensa local traducciones de Baudelaire, J. Lemaitre, P. Bourget, [...] etc. entre otros" (2001: 242).

13 "Podía pasar horas enteras disertando entre astronomía y teosofismo" (2001: 242).

${ }^{14}$ Sin embargo, lo consideramos un autor canario siguiendo la caracterización sobre literatura canaria de María Rosa Alonso: "la que en las islas se cultiva ya por los escritores en ella nacidos, ya por los que en ellas han vivido buena parte de su vida" (1991: 196) y según Sebastián Padrón "por haber plasmado la mayor parte de su obra en Tenerife, por ser descendiente de una familia de rancio abolengo isleño, incluimos a Manuel Verdugo Barlett como uno de los poetas canarios más influyentes de su época." (Padrón, 1999: 318).

${ }^{15}$ Don Federico Verdugo y Massieu, natural de Tenerife.

${ }^{16}$ Julia Ignacia Bartlett de Tarrius, hija del Cónsul de Gran Bretaña en las Islas Canarias, Mr. Richard Bartlett. 
los escasos cuatro años que desempeñó la carrera militar, estuvo destinado en Santa Cruz de Tenerife, luego en Mahón, de nuevo en Santa Cruz y por último en Las Palmas de Gran Canaria. Con veinticuatro años pierde a su padre (1901). En 1903 envía desde Las Palmas algunas composiciones poéticas a la revista de Santa Cruz de Tenerife Arte y Letras. Ese año se retira de la vida militar y se marcha de las Islas, de las que está fuera unos cinco años. Es la época de sus viajes. A continuación, dejamos la respuesta de Manuel Verdugo a la pregunta que le hizo Luis Alejandro ${ }^{17}$ cuando le pregunta por qué razón se retiró de la vida militar:

Ya le indiqué que no sentía un gran amor por la profesión. Esto aparte, existían otros motivos de índole espiritual. Durante los años que estuve destinado en Madrid, después de mi salida de la Academia, entablé amistad con escritores y poetas y alternaba constantemente con ellos.

- Y entonces brotó, salió a la superficie el manantial poético que estaba soterrado en su alma.

-Exactamente, mis inquietudes de la adolescencia, aquella cosa vaga e imprecisa que me impedía desear ninguna profesión o carrera con ímpetu y afán, quedó concretada en una eclosión, explosión o erupción de versos (Verdugo, 1946).

Uno de los aspectos que más llama la atención es el de su vasta preparación cultural adquirida en ese tiempo, de 1903 a 1909. Viaja por Madrid, Portugal, Barcelona, París, Pompeya, Nápoles, Sicilia, Roma, Suiza, Bélgica, etc., los centros neurálgicos de la época, en los que se impregnó de cultura humanística. En Portugal vive una temporada con su gran amigo Villaespesa. En 1906 se traslada a Italia donde vive casi un año, especialmente en Nápoles. Al siguiente año (1908), llega a Tenerife para fijar su residencia en La Laguna. Manuel Verdugo tenía entonces treinta años. Estos viajes por Europa consolidarán esa nota de cosmopolitismo que caracteriza su poesía.

Cuatro fueron los poemarios que Verdugo publicó en vida: Hojas, publicado en Madrid en 1905; Estelas, publicado también en Madrid por la editorial Renacimiento en 1922; Burbujas, publicado en La Laguna en 1931; y Huellas en el páramo, publicado por el Instituto de Estudios Canarios en La Laguna en 1945. De sus incursiones en la prosa tenemos: Autobiografia, de 1922; y Fragmentos del diario de un viaje, publicado en Santa Cruz de Tenerife en 1928 por la editorial Hespérides. Posteriormente, apareció una antología de Páginas de Manuel Verdugo, Santa Cruz de Tenerife, 1928. Fruto de su labor como dramaturgo son las obras: Lo que estaba escrito, estrenada en el Teatro Leal de La Laguna en 1919; Las fronteras del mal y Jugando, diálogo de relámpago, ambas publicadas en la revista Castalia en 1917. Falleció en San Cristóbal de La Laguna en 1951.

${ }^{17}$ Cf. Luis Alejandro, "Un artífice del verso: Manuel Verdugo, parnasiano y satírico", en periódico La Tarde, página 3, el día 13 de septiembre de 1946, Tenerife. 


\title{
2. ELEMENTOS MÍTICOS GRECOLATINOS
}

\subsection{BACO}

El primer elemento mítico que encontramos en la edición de Lázaro Santana es el dios romano Baco, "llamado también por los griegos Dioniso e identificado en Roma con el antiguo dios itálico Liber Pater y, siendo en esencia en la época clásica, el dios de la viña, del vino y del delirio místico" (Grimal, 1979: 140). Esta divinidad aparece en el poema titulado "Champagne" perteneciente al primer libro de Verdugo, Hojas. En general, el poema nos cuenta como el "pensamiento loco" del autor crea un "campo ideal de las quimeras", como el champagne le inspira y le hace ver imágenes, un "desfile fantástico" que provocan en él "sensaciones nuevas" y cómo la embriaguez le llega a hacer ver al mismo dios Baco. Se trata de uno de los poemas en los que Lázaro Santana ve reflejado ese carácter uranista de la poesía de Verdugo, quien muestra en este poema que se siente atraído por un muchacho de "clásica belleza". Acerca de este poema, dice Lázaro Santana: "Tanto la advertencia enigmática como la invocación fervorosa traslucen un tono de complicidad; [...] lo que le permite advertir a un dios de un mancebo desnudo" (1989: 16). Valbuena Prat afirma de esta composición que es "una anacreóntica de tipo fin de siglo, una bacanal de áureas llamas" (1937: 106). Por su parte, María Rosa Alonso, también coincide diciendo: "está en la línea de esas escasas pero excelentes composiciones dinámicas del autor, en las que el soplo dionisíaco del vendaval que agita los pámpanos enciende con licor el numen del poeta" (2009: 42). En definitiva, interpretamos que se trata de un poema de crítica hacia los convencionalismos sociales que le hacen sentirse triste porque no ve lugar para él en la sociedad; al mismo tiempo siente que de alguna manera no encaja y recurre al champagne (alcohol) para dejar vagar su "pensamiento loco" con el que se siente cómodo y alivia sus penas. Finaliza la composición con un "himno audaz" provocado por la embriaguez del alcohol que le lleva hacia una atmósfera mitológica con la que queda maravillado:

\author{
Yo levanto mi copa \\ y se la brindo llena \\ a un mancebo desnudo, \\ de clásica belleza, \\ que me tiende los brazos, sonrientes, \\ entre el vapor de la luminosa niebla. \\ ¡Es el divino Baco \\ que ha dejado el Olimpo por la tierra! (pp. 26-27)
}

Por otro lado, destacamos que tres de las características temáticas del Modernismo son la búsqueda de un mundo exótico como evasión de la sociedad actual, el erotismo como liberación y paz, y la utilización de mitos clásicos como fuente de inspiración; características que se sincretizan en este poema y que seguiremos viendo en otros posteriores. 
"A Urania" es el título de otra de las composiciones de su primer libro, Hojas, que mejor expresa el fondo general de su poesía: la disconformidad con el mundo en que vive y su dolor ante la cruel realidad con la que no logra sentirse cómodo e identificado. Urania, la famosa "musa de la astronomía y astrología, se la representa con las facciones de una joven hermosa que porta una corona de estrellas, un manto azul cuajado de estrellas y, esparcidos a sus pies, algunos elementos matemáticos" (Howatson, 2005: 868). Urania es elegida para crear una extraordinaria metáfora entre el cielo, como si fuera la tierra, y las luces de las estrellas, como las mentiras y falsos estereotipos de la sociedad que no coinciden con el interior del autor y le hacen sentirse incómodo e indignado con la falsedad que le rodea. Esta es otra de las composiciones que Lázaro Santana destacó, junto con "Champagne", donde aparece tímidamente ese carácter uranista. Aunque Santana no realizó un análisis de por qué llegó a estas conclusiones con estos poemas, creemos que podría ser por versos que hacen que "Verdugo parezca un iniciado en ese alfabeto incomprensible" (1989: 17) referido a su homosexualidad, que le hace sentir diferente al estar mal vista por la sociedad, recibiendo burlas y ataques. El desajuste que se da entre su sentir interior y los parámetros de la vida y la sociedad de su tiempo, tiene como consecuencia un conflicto interior dentro de sí, una lucha y resignación a lo que sucede para mantener una falsa calma con la sociedad. Verdugo nos muestra con este sincero poema que vive con indignación y resignación en una sociedad en la que los ciudadanos, muchas veces, tienen que mentir acerca de sí mismos para poder encajar sin ser discriminados. Recordemos que Verdugo procedía de linaje militar donde la visibilidad de homosexuales era prácticamente nula. Esta represión consigo mismo le hace sentirse angustiado, enfadado y desafiante a la vez. Hace un estupendo uso de las metáforas para crear una crítica mágica a través del celeste misterio del don de Urania:

Como también el cielo nos engaña, detesto el resplandor de las estrellas y las noches azules y apacibles; quiero noches sin astros, noches negras, en que copie fielmente el firmamento este fondo que llevo de tinieblas.

Es peligroso para ciertas almas el contemplar esa brillante esfera en donde un ser eterno, omnipotente, con regueros de luz marcó sus huellas y con un alfabeto incomprensible el secreto escribió de la existencia. Tengo miedo a mirar ese infinito. ¡Cuántas mentidas luces centellan atrayendo la mente del incauto, que en sus bellos cambiantes se recrea! (p. 33-35) 


\subsection{APOLO}

La presencia de la deidad de Apolo es reiterada en varias composiciones. La primera, la encontramos en el poema titulado "El alma y el cuerpo". Apolo "es el más polifacético de todos los dioses: fue considerado como el dios de la luz, de la música, de la poesía, de las bellas artes, de las cosechas, de las armas, de las purificaciones en general. [...] Bello joven de formas atléticas acompañado por el arco, la lira, el trípode y coronado con hojas de laurel” (Grimal, 1979: 36-37). Verdugo proclamará a la escultura de Apolo, "Apolo de mármol", como norma de las artes, de inspiración masculina, vigorosa y fuerte. Esta visión totalizadora del hombre parece corresponderse con el dios. En general, el poema versa continuamente acerca de una disputa entre el alma y el cuerpo, y la queja que alza el cuerpo fisico carnal a pesar de ser perecedero, frente al alma que es eterna.

Un Apolo de mármol, frágil forma,

en su triunfante desnudez prefiero

a la visión inmensa de los mares

y al piélago infinito del desierto...

¿Por qué desdeñas la hermosura humana?

¡Maldigo tu desprecio!

Es para el alma la carnal belleza

lo que bella palabra al pensamiento;

si tanto amas a Dios, alma del mundo,

tienes que amar también al Universo;

¡y en la tierra se apoya la rodilla

para postrarse y adorar al cielo! (pp. 48-49)

Otro de los poemas en que se deja ver al dios es el titulado "El laurel de Apolo". Recuérdese que este hijo de Zeus y Leto, "no limitó sus amores a las mujeres; también amó a los muchachos. Los más célebres son los héroes Jacinto y Cipariso" (Grimal, 1979: 36). Así, en este poema confluyen la presencia de Cipariso, joven amado entre otros por Apolo, y la de Dafne. En el mito de Cipariso, por accidente, "el joven mata a su eterno compañero, un ciervo sagrado. Desesperado, el joven quiso morir y pidió al cielo la gracia de que dejase que sus lágrimas fluyeran eternamente dando así lugar al ciprés, el árbol de la tristeza" (Grimal, 1979: 106). Por otro lado, es muy conocida la leyenda de Apolo y Dafne, "amó a la ninfa Dafne, pero la ninfa no correspondió sus deseos y huyó a las montañas. Cuando estaba a punto de ser alcanzada dirigió una plegaria a su padre, Peneo, suplicándole que la metamorfosease para permitirle escapar. Su padre consintió en ello y la transformó en laurel, árbol consagrado a Apolo" (Grimal, 1979: 36). Para Sebastián Padrón, es una "magnífica poesía de forma y de fondo, donde late un hondo sentimiento de nostalgia, que destruye por sí solo el tópico de la supuesta frialdad de la obra de este magnífico poeta" (1966: 321). María Rosa Alonso interpreta que "Apolo, en su santuario en ruinas, le sirve de pretexto a Verdugo para una nostálgica evocación a la amada vida, pasada y muerta, del paganismo. Véase cómo, en un paisaje de mármoles y columnas rotas entre las ortigas, el poeta, si bien siente el paso de los siglos, no actúa reflexivamente para hacer una consideración a lo Rodrigo Caro acerca de la brevedad de la vida, sino que la emoción de las ruinas le sirve, una vez más, para expresar su amor 
por la belleza antigua, prestigiada por el morbo melancólico del pasado" (2009: 84). Se trata de un poema que rebosa un intenso y bien asimilado parnasianismo. Simpatiza lo bello con la antigüedad clásica. Recordemos que lo que impulsa a un parnasiano a emplear con frecuencia los temas clásicos no es simplemente un deseo de huida, sino, más bien, el deseo de crear un mundo de hermosas imágenes y musicalidad que sirva de compensación al materialismo y falsedad de los tiempos modernos, tema constante en la poesía de Verdugo.

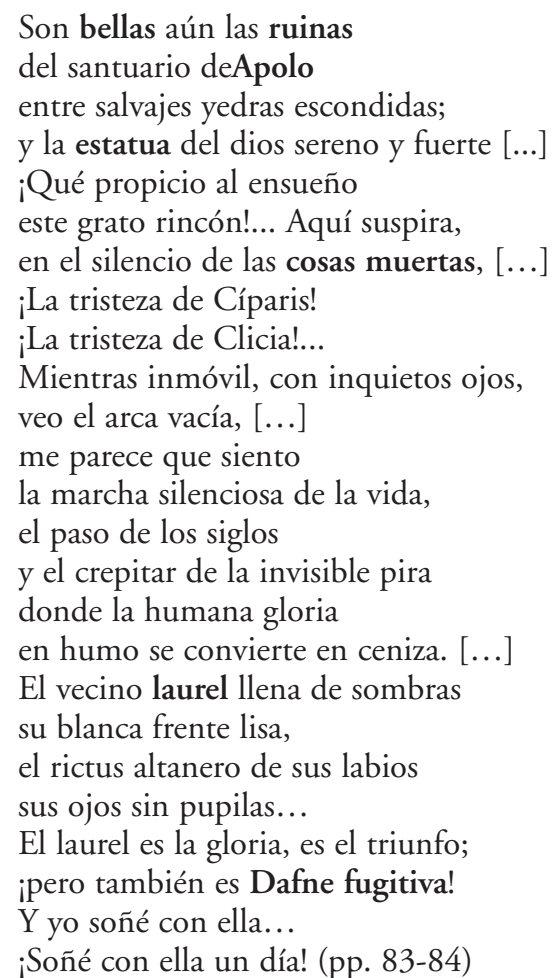

Otra de las composiciones en las que aparece esta divinidad es en la titulada "Rubén Darío". Versos que Verdugo le dedica con gran admiración y maravilla al máximo representante del modernismo literario en lengua española. Quizás, la intención de Verdugo fue la de crear cierto paralelismo entre este y el dios Apolo, símbolo de inspiración profética y artística, patrón de la música y la poesía donde su lira se convirtió en su atributo común. Resalta una de las características de este dios llamándolo Apolo Musageta; y es que Apolo era jefe de las musas al igual que Rubén Darío era líder entre los modernistas. Interpretamos que la intención de Verdugo es la de elogiar al nicaragüense.

Ya descansa el espíritu del errante poeta, el de faz impasible; pero siempre agitado por sublime delirio, el delirio sagrado y tal vez doloroso de Apolo Musageta (p. 155) 


\subsection{AFrodita / VenUS}

Las referencias a la diosa griega Afrodita son constantes en la obra de nuestro autor. Esta diosa de la belleza, el amor, el deseo, la lujuria, el sexo y la reproducción es recordada, sobre todo, por uno de los momentos más bochornosos en su vida amorosa y que Pierre Grimal nos relata de la siguiente manera:

Afrodita es la diosa del amor, identificada en Roma con la antigua divinidad itálica Venus. [...] Afrodita casó con Hefesto, pero amaba a Ares, el dios de la guerra. [...] De madrugada, los dos amantes fueron sorprendidos por el Sol, que fue a contar la aventura a Hefesto. [...] Una noche en que los dos amantes se hallaban en el lecho de Afrodita, Hefesto cerró una red sobre ellos y llamó a todos los dioses del Olimpo. [...] La diosa también amó a Anquises. [...] Las iras y maldiciones de Afrodita fueron famosas (1979: 12).

Verdugo constantemente se siente un pagano que se recrea en el pasado, sentimiento que le acompañará durante toda su vida. Así, su amor es también pagano, lo que le hace soñar con el mundo de los dioses y profanar recintos cristianos como este, titulado "Solo I". Para Juana Rosa Suárez Robaina, este poema "parece debatirse en su doble condición de creyente y pagano" (1992: 14). Sin embargo, nos deja un detalle palpable; Verdugo se siente angustiado con la religión cristiana, porque en ella se siente reprimido y no llega a encontrar esa liberación que sí encuentra en la religión griega, con la que se siente más identificado, más cómodo. Una de las temáticas usuales en el Modernismo es el sincretismo religioso como el que nos encontramos: cristianismo y paganismo. Esta adoración hacia ambas religiones por parte del poeta la comentaremos con más detalle en el poema "Vértices luminosos". También, podemos ver la constante preferencia de Verdugo por las estatuas ${ }^{18}$ "estatua de Afrodita"; la presencia de estatuas, esculturas, figuras, etc., son persistentes a lo largo de su obra. Por otra parte, María Rosa Alonso, observa en este poema que "el trato con los objetos del paisaje le sirve de piedra de toque y referencia a la evocación antigua. Tan sensibilizado está para el paisaje neoclásico, que en la catedral gótica y en medio de Castilla se advierte la incomodidad del europeo y romano a destiempo" (2009: 79).

Hay un Cristo de agónica mirada, [...]

Y lloro por mí mismo... Yo profano con los anhelos de un amor pagano la santidad de la mansión bendita:

${ }^{18}$ En este sentido puede consultarse el artículo de G. Santana Henríquez, "Agalmatofilia y otras excentricidades amorosas-sexuales de la Grecia Antigua”, en V. Escudero, N. Gómez, A. Narro (eds.), Omnia vincit Amor. Amor i erotisme a les literatures clàssiques i la sua recepció, Amsterdam, 2015, pp. 221-236. 
¡Sueños con las riberas luminosas

donde en claros altares y entre rosas

besaba el sol la estatua de Afrodita! (p. 89)

La diosa del amor continúa apareciendo, ahora, bajo la denominación de Venus. Venus es considerada también "la diosa de los jardines" (1979: 12) y Verdugo la sitúa "En la terraza de un jardín desierto". En la mayoría de ocasiones, nuestro autor dibuja a Venus en medio de descripciones paisajísticas como ocurre en "Ensueños líricos". Composiciones como estas son las que hacen recordarnos la faceta artística de nuestro autor que se dedicó a la pintura impresionista. En el impresionismo, la fuente de inspiración proviene de los paisajes. Los pintores expresaban su arte a través de la naturaleza y el contacto de los objetos con la luz. Buscan centralizarse fundamentalmente en la luz y no en la forma, por eso, las formas se difuminan bajo el influjo que la luz les imprime a los objetos, como ocurre en este poema al describir a una Venus desdibujada por el brillo "luce Venus, su fulgor incierto", o cuando describe la salida del sol en el cielo "sonrisa luminosa". Para María Rosa Alonso "la visión de la luz tamizada, de paisaje impresionista, se advierte en un paisaje pictórico e irreal. [...] Visión estática del mar que parece muerto" (2009: 77):

En la terraza del jardín desierto, contemplamos el mar: parece muerto, como tu voluntad, como la mía.

Aún luce Venus, su fulgor incierto

Es de una plácida melancolía...

El cielo taciturno, por Oriente,

Inicia una sonrisa luminosa.

El Alba... (p. 149-150)

También, en "Prosopopeyas" aparece la diosa nombrada por su hijo Eros, fruto de "los amores con Ares" (1979: 11). El poema nos habla acerca de la relación amistad-amor, quizás, refiriéndose a la confusión que se puede crear con el amor de una amistad y el amor de un enamorado y las consecuencias angustiosas que puede tener el enamorarse de un amigo:

“¡Por qué en ciertos instantes dices que eres mi hermano,

y otras veces te obstinas en que soy tu mamá?”

Y el Amor respondióle, con la faz sonriente:

"Soy el hijo de Venus...; ¡demasiado lo sé!

$\mathrm{Ni}$ te quiero ni admiro... ¡Huye, pues, imprudente,

que si ves a mi madre, si la miras de frente,

con mis débiles brazos de niño te ahogaré!” (p. 160)

"Paisaje" es otra de las composiciones que describe la belleza paisajística del amanecer con estilo impresionista y que vuelve a desdibujar a una Venus reluciente situando a la diosa en el lugar para aportar belleza. María Rosa Alonso, nos cuenta que "los paisajes de Verdugo son muy realistas, muy poco objetivos y muchas veces son simbólicos. En este aspecto está más cerca de los modernistas. Le sugestiona casi siempre un paisaje, que ve y siente como pintor y artista impresionista" (2009: 76): 
Tiñe el cielo un albor nácar y rosa

en que la agreste sierra delinea

sus monstruosos picachos. Centellea

Venus como una joya esplendorosa. (p. 170)

También, aparece en la composición que le dedica al ateniense Alcibíades, que lleva por título su nombre y, del que hablaremos posteriormente en el apartado 4.3. Elementos de la tradición clásica grecolatina, dotándolo de las cualidades de las diosas Venus y Minerva:

Alcibíades

Ama el estudio y el placer que enerva:

es un hijo de Venus engendrado

a la sombra del casco de Minerva. (p. 185)

Recordemos que Venus era una importante diosa romana relacionada principalmente con el amor, la belleza y la fertilidad, rasgos que el autor menciona sutilmente y haciendo alarde de su conocimiento e ingenio. En "Venus centellea" vuelve Verdugo a describirnos, casi con las mismas palabras que en el poema "Paisaje", a una Venus reluciente, comparándola de nuevo con una joya:

El rostro de la monja... Su labio balbucea

una súplica estéril al cielo indiferente,

donde el claro diamante de Venus centellea. (p. 79)

\subsection{Pegaso}

En el poema "VIII En el reino de la poesía", Verdugo nombra a Pegaso, en relación con la palabra griega que significa "manantial. [...] Pegaso es el caballo alado que al nacer vuela al Olimpo donde se pone al servicio de Zeus llevándole el rayo (Grimal, 1979: 413)". Estos versos nos hablan del erigir de la poesía y de cómo él como poeta encuentra su iluminación en temas ignorados por la sociedad y en el mundo de la tradición clásica. La utilización del mito y, concretamente, de la mitología griega, constituye un elemento fecundante de la poesía parnasianista y modernista, dado que en ella descubrían verdades de validez universal, apropiadas para describir la situación presente en términos simbólicos.

Yo percibo en la sombra — sueño acaso-

ecos remotos de ignorada lira,

y el galope triunfante de Pegaso.... (p. 57)

En relación al tema de la poesía, expondremos la extraordinaria opinión que tenía Verdugo, de cómo la concebía y sentía. Esta mágica descripción la relató en el prólogo del libro titulado Alta Plática de Francisco Izquierdo en 1915:

Una orientación rectilínea en un libro de versos implica cierta fría premeditación que es incompatible con la sinceridad artística. Yo miro la Poesía como un surtidor cristalino que se eleva recto hacia el cielo, cual si quiera besar los astros, y se queja 
armoniosamente de su impotencia; pero que a veces se inclina hacia impulsos de opuestas ráfagas, y los irisados diamantes del divino surtidor se esparcen sobre la tierra y brillan sobre una flor; sobre una zarza, sobre una roca, sobre el mismo barro despreciable: doblemente despreciable si en él se ven las huellas de los hombres... (Verdugo, 1915: 14).

Otra referencia al fabuloso caballo la tenemos en el primer soneto de la serie "Buenos consejos". María Rosa Alonso define perfectamente esta serie de poemas de la siguiente manera: "son el doctrinal del cínico, del dandy finisecular, del hombre del momento, frente al romántico; en el estilo sentencioso del catecismo del cínico va escondida una ironía muy típica de Verdugo en la que, so capa de un humor acre, se encubre la ortodoxia de un moralista frustrado" (2009: 53):

Siempre que tengas sed, bebe en tu vaso.

Recuerda que en las pendientes, caminante,

que es muy fácil trocar en Rocinante

— si le cortas las alas_ - a Pegaso. (p. 69)

\subsection{ZEUS}

Desde el punto de vista de sus ideas religiosas, el propio Verdugo no has dejado una página de su autobiografía ${ }^{19}$ en la que resume brevemente su evolución espiritual:

De la pura y candorosa fe de mi adolescencia, pasé bruscamente a un materialismo estúpido, fruto de lecturas mal digeridas. Después, me refugié en una idea caótica de panteísmo. Más tarde la figura de Jesús me atraía como una estrella rutilante. [...] Después, harto de hacer carambolas teológicas con el pensamiento, me tendí a la sombra de Sócrates. Y así musité las palabras que dirigía a sus discípulos el amigo de Alcibíades (Verdugo, 1909).

La siguiente composición, "XVII vértices luminosos", recoge de nuevo el sincretismo religioso característico del modernismo. Alienta a las deidades Jehová, Zeo y Jesús a que oriente a la humanidad inconsciente, porque para él la sociedad está "marchita" y necesita aprender de sus dioses. Sin embargo, las historias de estos dioses ya no son recordadas si quiera en sus lugares de origen: el Gólgota, el Olimpo y el Sinaí, por lo que se hace remoto que la luz de sus hazañas no causen cambios en la concepción de la humanidad y, por consiguiente, de la vida. Interesante son las correlaciones divinas que hace en la siguiente composición:

${ }^{19}$ Manuel Verdugo (1909): periódico El Progreso: Diario Republicano los días 21 y 22 de septiembre. 
Jehová, Zeo, Jesús: Ígneo tridente, Magna constelación - triángulo inscrito en el cero que abarca lo infinito-: ¡Pon un crisma de luz en cada frente! La Humanidad bosteza indiferente, hallando el lirio de la fe marchito... $\mathrm{Ni}$ áurea leyenda ni sagrado mito surgen ya, como antaño, del Oriente... ¡Jehová, Zeo, Jesús! Voz angustiosa, ve a perderte con la noche silenciosa... ¡No hay un hueco en la tierra para ti! Bajo el cielo, sediento de plegarias, yerguen sus cumbres mudas, solitarias el Gólgota, El Olimpo, el Sinaí... (p. 68)

\subsection{PANDORA}

Pandora es nombrada por Verdugo en dos ocasiones, la primera en el poema titulado "Buenos consejos III" que versa acerca del origen y mito de esta. Pandora fue la primera mujer,

fue creada por Hefesto y Atenea, con ayuda de todos los dioses y por mandato de Zeus como castigo para la raza humana. Cada uno le confirió una cualidad, y, así, recibió la belleza, la gracia, la habilidad manual, la persuasión, etc.; pero Hermes puso en su corazón la mentira y la falacia. Pandora fue el regalo que todos los dioses ofrecieron a los hombres, para su desgracia después de que Prometeo, yendo en contra de su voluntad, le otorgara el don del fuego a la humanidad. (Grimal, 1979: 405).

Pandora es mayormente conocida por su mito relacionado con la famosa y más conocida caja de Pandora. Después de Zeus mandarla a Epimeteo, hermano de Prometeo, quien se dejó seducir por su belleza y la hizo su mujer. Pandora, picada por la curiosidad de saber qué había en la vasija que le confirió Zeus, la abrió esparciéndose así todos los males por la humanidad. Solo la esperanza, que había quedado en el fondo, no pudo escapar.

El muy amado sexo femenino

fue el origen fatal de nuestros males... [...]

¡Ninguno más feliz que el impudente

que se duerme tranquilo y sonriente,

reclinado en la caja de Pandora! (p. 71)

La otra alusión a la primera mujer, la encontramos en el soneto titulado "Dos bestias pura sangre" en el que dos mozos dormitan y se lamentan por el amor. Ambos definen e identifican el causante de su estado: para uno "el amor es un mito", para el otro "el amor es imbécil". Ambos sueñan:

Van los sueños del uno a su yegua Pandora; van los sueños del otro a la perra que adora, y ambos roncan tranquilos en el amplio salón (p. 142) 


\subsection{NARCISO Y ECO}

El título del siguiente poema cuenta la historia del joven Narciso. "Era un joven muy hermoso de la mitología griega que rechazaba a todas las doncellas que se enamoraban de él, entre ellas estaba la ninfa Eco. Para castigar a Narciso por su engreimiento, Némesis, la diosa de la venganza, hizo que se enamorara de su propia imagen reflejada en una fuente. En una contemplación absorta, acabó arrojándose a las aguas" (Grimal, 1979: 370).

\section{Narciso}

En el jardín, Narciso, adolescente, reposa, solo, en desnudez divina; con gracioso abandono se reclina sobre el borde musgoso de una fuente. En el agua tranquila, transparente, ve copiada su carne alabastrina, y el insensato, estremecido, siente que un anhelo imposible le domina. En vano lleva el viento hasta su oído el apagado, trémulo gemido que lanza Eco al verse despreciada. Él, desdeñoso, corazón de roca, al líquido cristal junta la boca para besar su imagen reflejada. (p.75)

\subsection{EROS}

Verdugo utiliza a lo largo de su obra toda la gama de posibles nombres para el dios del amor: Eros, Cupido, Amor y Anteros. Destacaremos dos de los poemas en los que se cita y describe a nuestro dios con dos impresionantes sonetos, dedicados uno a "Amor" y otro a "Eros", encontrándonos con los tópicos más representativos de este dios: cabello rubio y rizado, rostro juvenil, flechas, carcaj, alas, de pequeña estatura (típica imagen alejandrina), etc., y destacando la afirmación de Pierre Grimal "en vez de ser un dios omnipotente, es una fuerza perpetuamente insatisfecha e inquieta" (1979: 171). Ambos poemas constituyen dos de las composiciones más bellas de las dedicadas al dios del amor.

Amor

Definir el Amor... Será posible cuando se pueda disecar un beso, encerrar en un molde lo intangible y de un suspiro conocer el peso.

Dejemos que el Amor, dulce o terrible, sostenga el mundo entre sus alas preso. ¿Es hermoso, gentil, grande, invencible? Definir es pensar, y amor... no es eso. 
Hay fuerzas triunfadoras de la muerte, emanadas de Dios, como Él, sin nombre, y el Amor, entre todas, las más fuerte: ¡vórtice de atracción a lo divino, que la infinita pequeñez del hombre arrebata en su inmenso torbellino! (p. 76)

\section{Eros}

Busca un rayo de sol de primavera en el rostro pueril de Eros dormido; los rizos de su blonda cabellera brillan con el fulgor de oro bruñido. Es su boca purpúrea hechicera, un diminuto corazón partido; cada pestaña, flecha traicionera, dardo de luz de su carcaj temido. Hay en sus alas cortas y sutiles el bello tornasol, inolvidable, que tienen nuestros sueños juveniles, y tibio soplo de sus labios mana, que esparce un polen místico, impalpable, como el secreto de la vida humana... (p. 165)

Esta imagen podría completarse con los poemas: "Junto a un alma inquieta" y "Prosopopeyas". El primero versa sobre la herida causada por el "arquero infante" y el segundo define la idea de dios caracterizado como bello, gracioso, rubio, fresco y traidor, hijo de Venus en donde aborda la relación amistad-amor:

Junto a un alma inquieta

Sobre todos los vicios y virtudes, sobre todas las cosas se alza el pequeño déspota triunfante cínico y bello deshojando rosas. ¡Ay de ti, si jinete en el pujante potro de la ilusión, suelta la brida corres en busca del arquero infante para en el pecho recibir la herida! El rubio sagitario es un vampiro que tras herirte sorberá tu vida... [...] Y si austero, degradando tu conciencia, observas la existencia con un hondo sentido religioso, entonces... notarás la omnipresencia del Amor hecho carne... ¡del Coloso! (pp. 80-81)

Prosopopeyas

La Amistad tiene cara de muy pocos amigos... os lo juro; la he visto... y también vi al Amor Éste es bello, gracioso, rubio como los trigos, fresco como las rosas, dulce como los higos; 
pero... muerto y un tanto vanidoso y traidor.

La Amistad, que acechaba al Amor, con la mano

le hizo señas, al verle y grito: "Ven acá:

para mí eres un primo, sólo un primo... lejano.

¿Por qué en ciertos instantes dices que eres mi hermano,

Y otras veces te obstinas en que soy tu mamá?"

Y el Amor respondióle, con la faz sonriente:

"Soy el hijo de Venus...; ¡demasiado lo sé!

$\mathrm{Ni}$ te quiero ni admiro... ¡Huye, pues, imprudente,

que si ves a mi madre, si la miras de frente,

con mis débiles brazos de niño te ahogaré!” (p. 160)

M. Martínez, en su trabajo "Un modernista parnasiano en la literatura canaria: Manuel Verdugo", dedicó un apartado a los aspectos relacionados con el amor en la obra de Verdugo, especialmente en lo que concierne a su visión de Eros, dios griego del amor, y del que tomaremos algunas de las citas de su pequeño catálogo dirigidas a nuestro personaje:

a) Para la cuestión de los dardos, flechas, carcaj, etc.:

El poeta gigante

del amor y el ensueño

supo lo que es llorar arrodillado

ante el león rampante de los celos,

y lo que es implorar inútilmente

al voluble flechero

cuando se aleja irónico y altivo

rotas las alas y el carcaj deshecho... (p. 128)

\section{Anacreonte}

¡Oh, poeta divino

de los amores fáciles, de las danzas y el vino!:

¿qué importaba que Eros te clavase algún dardo

si el temible chiquillo, por curarte la herida,

restañaba la sangre son sus dedos de nardo? ... (p. 174)

Rosa de trapo

¡Rompe, Cupido, la oxidada flecha,

que deshojó una rosa contrahecha

sobre el ara desnuda de tu altar! (p. 123)

b) Para la relación de Eros con el fuego, antorcha, etc.:

¿Reencarnación?

Esa sombra implacable que te hiere,

¿es el bruno rapaz, el propio Anteros,

el vengativo, el fuerte,

y es la llama siniestra de su antorcha

la que en su noche esplende?... 
c) Para el tema de la ceguera de amor:

Desaliento

Pero tiene la Vida una faz tan cansada...

La Amistad hoy ha herido con su mano enguantada...

Hoy con sus ojos ciegos ha llorado el Amor... (p. 181)

d) Para la relación Amor-melancolía:

El veneno de la melancolía

Hoy se baña mi alma — que cobarde corría

Bordeando el torrente del humano dolor-

En el suave remanso de la melancolía,

Donde suele mirarse, pensativo, el Amor. (p.189)

e) Para el tema de las heridas del Amor:

Voces de antaño

— Socorredme: estoy herido!

- ¿Por quién, paje seductor?

Señora, por un bandido

tan bello como atrevido;

luchamos y me ha vencido...

—Le conozco: es el Amor. (p. 190)

A Francisco González Díaz

El Amor quiso herirte; pero huyó presuroso

al ver que, con sarcasmos, eras tú quien le herías... (p. 106)

f) Para la relación Amor-beso:

En la penumbra

¿Qué dejó en su memoria yermo helado-, el Amor al pasar?... Furtiva huella:

¡Sólo un beso frenético robado

a una mujer apasionada y bella! (p. 176)

g) Amor, engendro, impuro:

A Mademoiselle P.

Cupidillo venal, engendro impuro, ¡con qué cínica gracia me has robado y qué final hallaste, prematuro! (p. 169)

h) Amor voluble:

Las dos voces

—Parece en tu clepsidra cada gota

lágrima del Dolor...

- Y en la tuya... ¿qué habrá cuándo esté rota

Como un juguete del voluble Amor? (p. 161) 
i) La relación Amor-Arte:

El poeta caudillo

-Dispuesto a sucumbir sin entregarte,

tremolas como lábaro fulgente,

impoluto ideal de Amor y Arte. (p. 58)

M. Martínez, después de confeccionar este pequeño catálogo de citas, concluye en que esta predilección de Verdugo por Eros se explicaría, en parte, por la condición homosexual de nuestro autor, "en detrimento de la de Afrodita-Venus, que se encuentra muchísimo menos en su obra” (1999: 52).

\subsection{Filemón y BAUCIS}

"Filemón y Baucis" es el título del siguiente poema. Fue el único matrimonio en la ciudad de Tiana (Capadocia) en dejar entrar en su casa a Zeus y a Hermes que, gracias a este gesto, fueron salvados de la inundación que provocó Zeus en la ciudad como venganza por la negativa del resto de habitantes de darle cobijo a él y a Hermes. Como deseo que pidió el matrimonio cuando Zeus les preguntó, desearon ser guardianes del nuevo templo, vivir la mayor cantidad de tiempo posible juntos y morir al mismo tiempo. Tras su muerte, Zeus los convirtió en árboles que se inclinaban uno hacia el otro frente al templo que en otro tiempo había sido su cabaña mientras ellos decían sus últimas palabras. A Filemón lo convirtió en roble; y a Baucis, en tilo. Con su típica y peculiar forma de burlarse, este es otro de los poemas en los que Verdugo muestra una actitud negativa frente al matrimonio. Retrata a Filemón haciendo memoria sobre cuánto tiempo lleva casado con Baucis, que apenas es un mes, y que con desánimo muestra que se la ha hecho muy largo; "ese aburrimiento feroz que Verdugo describe en el amor de unos jóvenes recién casados” (Lázaro Santana, 1989: 20).

Rompe el silencio el joven, y así dice posando en ella su glacial mirada:

- Hace un mes nos casaron...

¿Un mes?... No, tres semanas.-

Y luego, bostezando levemente:-

¡Estas noches de invierno son muy largas!

Pero, ¿en qué piensas?, dime...

Te encuentro distraída... ¿Qué te pasa?

—¿En qué pienso? —respóndele la hermosa-.

En nuestra dicha... Ya lo ves: jen nada! (p. 94)

\subsection{ANTEROS}

Anteros aparece en el poema titulado "¿Reencarnación?" donde Verdugo imagina la figura de Anteros. En la mitología griega, Anteros es la personificación del amor correspondido y vengador del amor no correspondido. Era hijo de Ares y Afrodita, quienes lo dieron a su hermano Eros, que estaba solo, como compañero 
de juegos. Originalmente Anteros se opuso a Cupido y luchó contra él, conflicto que también se concibe como la rivalidad existente entre dos amantes. Anteros castigaba a los que despreciaban y no correspondían al amor de otros. Se le suele representar como un hermoso joven de larga cabellera con alas de mariposas y algunas veces con flechas y un arco. Versa sobre un dios muy joven destinado a vivir entre la plebe.

Esa gracia pueril de su figura,

¿qué nube la ensombrece?

Como la de Antinous, es tu mirada,

trágicamente verde

como el mignon de Adriano, te sonríes

como risa doliente.

¿No concibes amor sin sacrificio?...

Esa sombra implacable que te hiere,

¿es el bruno rapaz, el propio Anteros,

el vengativo, el fuerte,

y es la llama siniestra de su antorcha

la que en su noche esplende?...

Con ansias de algo ignoto

tu espíritu pagano se estremece

cuando sueña a las sombras de mirtos

que en mi jardín florecen...

Eres un dios muy joven,

castigado a vivir entre la plebe,

y a cada amanecer lloras nostalgias

de siglos que vuelven.

Como la de Antinuos es tu mirada,

trágicamente verde,

y yo he llegado hasta su fondo negro...

¡Tu querida es la Muerte!

Sé que naciste demasiado tarde...

No importa... No te inquietes... (p. 139)

\subsection{2. ÓnFale y HérCules}

En los ideales y temas propios de los movimientos literarios, modernismo y parnasianismo, que a su vez se encuentran en la obra de nuestro autor, hallamos un extraordinario entusiasmo por la belleza como un valor independiente. "La práctica del arte por el arte, en el sentido de que lo bello puede asimilarse sin identificarse con la verdad mediante un sentido estético totalmente independiente de nuestra valoración moral" (Marcos Martínez, 2001: 241). Por otra parte, volvemos a encontrarnos con el sincretismo religioso (cristianismo y religión griega) y con la presencia de la "escultura" relacionada con lo bello, que en esta ocasión hace referencia al cuerpo humano. En las dos primeras estrofas del soneto, titulado "Poder de la belleza", nuestro autor nos cuenta que vemos la belleza de Dios reflejada a través del cuerpo carnal de las personas, ya que esa hermosura proviene de la mano creadora y moldeadora de Dios. De esta manera, concluimos que para Verdugo el Dios cristiano es bello 
y portador de belleza y, que además, Verdugo es capaz de ver esta belleza desde la perspectiva de ambas religiones:

¡Dejó sus huellas en la arcilla impura

La omnipotente, la invisible Mano!

El que adora la física hermosura

es que vislumbra a Dios tras de los humano...

Yo admiro la carnal, viva escultura,

con ojos de creyente y de pagano. (p. 141)

En la tercera estrofa del soneto aparecen citados Ónfale y Heracles. Quizás, de esta reina de Lidia, Ónfale, el episodio más famoso sea el que tiene que ver con su relación con Hércules. "Heracles, a quien los latinos llamaban Hércules, es el héroe más célebre y popular de la mitología clásica" (Grimal, 1979: 239). Siendo Hércules obligado a venderse como esclavo y servir durante tres años a su amo, fue comprado por Ónfale. Según Pierre Grimal "los autores se muestran especialmente pródigos en detalles acerca de los amores del héroe y la reina. Se han complacido en representar a Hércules vestido, a la moda lidia, con largos ropajes femeninos, mientras sentado a los pies de Ónfale, aprendía a hilar" (1979: 255). En este poema, hallamos constantemente un extraordinario entusiasmo por la belleza como un valor independiente:

Nada resiste a una mujer hermosa...

Ante Onfala, con mano temblorosa,

Hércules hila, tras besarle el pie;

Nuestro poeta termina y culmina el poema citando a un personaje de la vida cotidiana, como es la famosa y bella cortesana Friné, a quien su belleza la salvó de la muerte. Friné fue acusada de impiedad, una falta imperdonable en la Antigua Grecia junto al atrevimiento de compararse con la misma Afrodita. A petición de Praxíteles, la defendió Hipérides, quien fue incapaz de convencer a los jueces de su inocencia. Como último recurso, el artista desnudó a Friné, argumentándoles que no se podía privar al mundo de tanta belleza. Con esta estrategia, consiguió la absolución unánime del tribunal. María Rosa Alonso interpreta la composición de la siguiente manera: "hacia la busca del ilusionado mundo de la belleza, el poeta imagina un periplo estético. La voz del hombre cuerdo que vive con los pies en el mundo real no puede entrar en diálogo con la inefable palabra del poeta” (2009: 74). En esencia, el poema termina presidiendo a la belleza como motivo extraordinario inapelable, sirviendo incluso como justificación para absolver a un culpable en un juicio como le ocurrió a la famosa hetera Friné:

y la propia Justicia, tan austera,

deja un monumento su actitud severa

para rendir la espada ante Friné. (p. 141)

Con la misma historia vuelve nuestro autor a citar a la bella Friné, excusando su belleza como liberadora y valiosa en el poema titulado "A los poetas", característica 
propia de un parnasiano. María Rosa Alonso manifiesta este alzamiento de la belleza del arte de la siguiente manera: "reino de la poesía para el que desea inspiración viril, robusta, sana que toda generación necesita. Acentúa su creencia parnasiana de que el mundo poético es un mundo aparte y la actitud poética una actitud de minoría. Su idea de la independencia del arte o doctrina del arte por el arte la refleja en este poema" (2009: 74-75). Como parnasiano, desarrollaba el culto y la preocupación por la belleza y al arte, buscando la trascendencia de su obra alejado de la realidad:

Brille tras el encaje de la estrofa como desnuda espada el pensamiento; mostradles la verdad a vuestros jueces como Friné, sin velos (pp. 98-99)

Heracles vuelve a aparecer en "Las víctimas de Prometeo". Menciona el momento en que el héroe griego divinizado, Heracles, libera a Prometeo al pasar por la región donde se encontraba encadenado (en el Cáucaso), "liberó a Prometeo, cuyo hígado devoraba un águila que luego se regeneraba al momento" (Grimal, 1979: 455). Se apiada de él y con una flecha atraviesa el águila liberando a Prometeo de su castigo por haber robado el fuego a los dioses y dárselo a los humanos. Así, pregunta el poeta:

aquel mito pagano

en que un ladrón, tras de escalar el cielo,

purga el delito infame de robaros,

tiene un final que abate la justicia

y que proclama al fuerte soberano:

¿por qué Herakles liberta a Prometeo

si aún vosotros estáis encadenados? ... (pp. 196-197)

\subsection{Prometeo}

La siguiente composición titulada "La estatua", declara como Verdugo se siente atraído por la estatua de Prometo. Hay que advertir en Verdugo, "su gran admiración por el paganismo y la civilización romana le hace preferir la estatuaria antigua sobre las restantes artes" (María Rosa Alonso, 2009: 75). Prometeo es el Titán amigo de los mortales, honrado principalmente por "robar el fuego de los dioses, darlo a los hombres para su uso y posteriormente ser castigado por Zeus por este motivo" (Grimal, 1979: 455); si engañó a Zeus, fue por amor a los hombres. En el siguiente fragmento se observa cómo Verdugo se identifica con Prometeo en su deseo de ayudar al hombre. También, menciona el castigo de Zeus: el buitre que le devora el hígado regenerándose constantemente para así incrementar el castigo. Mientras, Prometeo permanece encadenado y totalmente indefenso. El poema habla de principio a fin de la atracción romántica y sexual que siente Verdugo por alguien de su mismo sexo, aspirando en uno de sus ensueños a darle vida a la estatua de Prometeo, alabándola constantemente con adjetivos como: "desnudez gloriosa", "divina belleza", "labios adorables", o "plástica maravilla”. El poeta se imagina besando a la estatua 
con la que mantendría en secreto "aquel beso absurdo" que nadie nunca conocerá: “¡nadie podrá leer nuestro secreto / en tus ojos impávidos de piedra” (1989: 145).

\author{
Plástica maravilla; \\ sueño mío imposible: ¡si pudiera \\ darte un poco del fuego de mis venas! ... \\ He querido animar, cual Prometeo, \\ una estatua soberbia, \\ y es buitre que destroza mis entrañas \\ mi vesánico afán, mi amor por ella. (pp. 144-145)
}

La composición titulada "Las víctimas de Prometeo" parece continuar con el episodio anterior. Cita ahora al dios Himeneo, "Himeneo es el dios que preside el cortejo nupcial. [...] Las tradiciones sobre su origen son varias" (Grimal, 1979: 268). Sin embargo, "todas estas leyendas están de acuerdo en el dato de la belleza del joven, el cual fue amado por Apolo, o acaso por Támiris o Héspero" (Grimal, 1979: 269). Por tanto, no sorprende la presencia de Himeneo, quien era amado por divinidades de su mismo sexo, si tenemos en cuenta la condición uranista de nuestro autor. Los atributos habituales de este dios son la antorcha, una corona de flores y una flauta.

\author{
¿por qué Herakles liberta a Prometeo \\ Si aún vosotros estáis encadenados? ... \\ Pero no importa, vuestra excelsa lumbre \\ diviniza a la tierra y al espacio; \\ luce como la antorcha de Himeneo \\ en las miserias del amor humano; \\ pone destellos de estelar pureza \\ en oscuros contactos, \\ y se dilata en piélago radiante \\ con el choque fecundo de los astros. (p. 196-197)
}

Podría intuirse "la puntual referencia a las estatuas hermosas y vencidas como a una evocación de la superioridad y libertad del mundo antiguo" (Lázaro Santana, 1989: 19).

\title{
2.14. CARONTE
}

Este poema, titulado "Divagación", nos advierte en sus dos primeras estrofas sobre el peligroso ansia de nuestro ser de querer descubrir el destino, advirtiéndonos que es mejor no anticiparnos porque podríamos descubrir realidades desagradables que impidieran hacernos disfrutar el presente. Este consejo los vemos patente en los versos siguientes: "iPor deshojar la flor de mi destino / me sangran hoy las temblorosas manos!". Las dos últimas estrofas nos aconsejan que es mejor ignorar nuestro destino hasta el día de nuestra muerte, momento que aprovecha Verdugo para introducir la figura de Caronte. "Caronte es un genio del mundo infernal. Su misión es pasar las almas, a través de los pantanos del Aqueronte, hasta la orilla opuesta del 
río de los muertos; éstos, en pago, deben darle un óbolo" (Grimal, 1979: 89). Aquellos que no podían pagar tenían que vagar cien años por las riberas del Aqueronte, tiempo después del cual Caronte accedía a llevarlos sin cobrar. Verdugo se preguntará a las puertas mismas del misterio de nuestro destino:

¿Estáis próximos ya o estás lejanos, términos luminosos del camino? Columbro a veces un fulgor divino... iy es la llama que brota en los pantanos!

Marchar... siempre marchar... Nada sabremos, hasta que oigamos con espanto un día el golpe rítmico de ocultos remos, y en la bruma tenaz del horizonte aparezca por fin, lenta, sombría, la barca de Caronte. (p. 148)

\subsection{TÁNTALO}

El siguiente poema titulado "La canción del eunuco", no es más que la representación del mito de Tántalo en el que la tentación nunca tiene satisfacción. "Tántalo es célebre en la mitología sobre todo por el castigo que hubo de sufrir en los Infiernos. [...] Se le culpaba por haber revelado a los hombres los divinos secretos de los dioses" (Grimal, 1979: 491). Otras historias cuentan que había sido castigado por "sustraer néctar y ambrosía durante los banquetes de los dioses para dárselos a sus amigos mortales" (Grimal, 1979: 491). La inmoralidad de Tántalo no acaba ahí, "parece que Tántalo inmoló a su hijo para servirlo como plato a los dioses" (Grimal, 1979: 491). El castigo de este "consistía en un hambre y sed eternas: sumergido hasta el cuello, no podía beber porque el líquido retrocedía. Y una rama cargada de frutos pendía sobre su cabeza, pero si levantaba el brazo, la rama se ponía fuera de su alcance" (Grimal, 1979: 492).

El protagonista del siguiente poema es un eunuco. Un eunuco, en la historia antigua, era un hombre castrado destinado a la custodia de las mujeres de un amo. De esta manera, el varón no representaría una amenaza sexual. El poema nos habla de ese deseo sexual que siente el eunuco que no puede saciar y de la muerte de las doncellas que custodiaba que causaron una inmensa soledad en él. Su amargura por las pérdidas le hace escapar hacia algún lugar donde intenta encontrar consuelo, pero sin éxito y, desesperado, se empieza a lanzar preguntas acerca de por qué le ha ocurrido esto. El símil con el castigo de Tántalo es palpable: al igual que Tántalo no podía saciar la sed y el hambre a pesar de tener agua y bebida muy cerca, de la misma manera, el eunuco no podía saciar su apetito sexual a pesar de custodiar a las doncellas por estar castrado. Un poema más, ejemplo del amor imposible; tema con el que seguramente se sentía identificado nuestro autor.

—Padezco como Tántalo: con lúbricas delicias

Sus ojos me brindaban... Mis párpados cerré.

Sus labios me humillaron con cálidas caricias; los míos se esquivan... Besar, ¿y para qué? (p. 166-167) 


\subsection{CRONOS}

En el siguiente poema titulado "Tic... Tac..." del libro de Verdugo Huellas en el páramo, aparece el Titán Cronos. "Crono es el más joven de los hijos de Urano y de Gea. Fue el único entre todos sus hermanos en intentar ayudar a su madre a vengarse de su padre. [...] Por un juego de palabras, se ha considerado a veces a Crono el Tiempo personificado" (Grimal, 1979: 120-121). Este titán es reconocido por su horrible proeza de comerse a sus propios hijos: "le habían dicho que sería destronado por uno de sus hijos, iba devorando a éstos a medida que nacían” (Grimal, 1979: 121). Otra de las características de los parnasianos que podemos apreciar en este poema es que encontraban en las leyendas griegas sentimientos como el amor, el deseo de la fama o el tránsito fugaz de la juventud. Verdugo en este poema empieza a meditar acerca del devenir del tiempo, de la hora de la vejez y de la muerte, de los cambios que producen "los minutos, las horas, los días, las semanas..." Utiliza a Cronos en representación del tiempo a quien llama "vampiro de la Vida, / destructor de ilusiones y sembrador de canas". El paso del tiempo es inevitable, tanto para el acontecimiento de situaciones provechosas como para el acontecimiento de situaciones maliciosas; el tiempo pasa por todos y por todo: "Consientes que madure toda fruta prohibida / y asesinas, en cambio, a las rosas tempranas”. Luego, con una actitud de sumisión se propone alejarse del tiempo, ve que se está haciendo viejo y aún no se hace a la idea: "Hoy rompí el calendario... y también el espejo / mis sienes ya platean... acaso llegue a viejo...". Termina el poema expresando una discordancia temporal con la que no se identifica:

y si llegas a herirme, restañarán mi herida los minutos, las horas, los días, las semanas...

Hoy rompí el calendario... y también el espejo,

Mis sienes ya platean... acaso llegue a viejo...

Diciembre agonizante, jotro año al abismo!

¿Diciembre, y en mi espíritu reina la primavera?

¿Por qué ha de preocuparme que un año nazca o muera?

¡Si todo cambia en torno, yo siempre soy el mismo! (p. 224)

\section{REFERENCIAS BIBLIOGRÁFICAS}

Alonso, Ma R. (1977): "La literatura en Canarias (del siglo XVI al XIX)" en A. Millares (ed.), Historia General de las Islas Canaria, ediciones Edirca, Las Palmas de Gran Canaria.

(2008) Todos los que fueron están, Dirección General del Libro, Archivo y Bibliotecas del Gobierno de Canarias, Islas Canarias.

_- (2009): Manuel Verdugo y su obra poética, editado por la Sociedad Estatal de Conmemoraciones Culturales y Viceconsejería de Cultura del Gobierno de Canarias, Islas Canarias.

_ (2010): En unas líneas..., Gobierno de Canarias, Islas Canarias.

Alzola, J. M. (1944): Autobiografias, Librería Hespérides, Santa Cruz de Tenerife.

Álvarez Cruz, L. (1949): Ecos (poesía), Ex-Libris, Santa Cruz de Tenerife. 
BlÁZQUeZ, F. (2005): Diccionario de mitología, editorial Verbo Divino, Navarra.

Daranas, M. - Sola, V. M. (1935): Páginas de Manuel Verdugo, Librería Hespérides, Santa Cruz de Tenerife.

GARCía GUAL, C. (1999): Introducción a la mitología griega, Alianza, Madrid.

Grimal, P. (1979): Diccionario de mitología griega y romana, Paidós, Madrid.

Howatson, M. C.: Diccionario abreviado de la literatura clásica, Alianza, Madrid.

IzQuierdo, F. (1915): Alta plática, Librería y tipografía Católica, Santa Cruz de Tenerife.

Martínez Hernández, M. (1996) [En línea]: Cultura grecolatina y literatura canaria: el mundo clásico en Manuel Verdugo (II), Universidad de La Laguna (Tenerife), trabajo de investigación perteneciente a la documentación científica de la ULPGC, Acceda <http://hdl.handle.net/ 10553/3919> [Consulta: 30/01/2017].

(1999): "Un modernista parnasiano en la literatura canaria: Manuel Verdugo" en G. SANTANA Henríquez y E. Padorno, (eds.), Varia lección sobre el 98. El Modernismo en Canarias, Las Palmas de Gran Canaria, Ayuntamiento de Arucas (Gran Canaria), Servicio de Publicaciones de la ULPGC, pp. 25-55.

(2001): "Capítulo 8. Cultura grecolatina y literatura canaria. El mundo clásico en Manuel Verdugo Barlett" en Ensayos de filología clásica, Santa Cruz de Tenerife, Servicio de publicaciones de la Universidad de La Laguna, perteneciente a la colección "Estudios y Ensayos".

Martinón, M. (2017): “Una obra teatral de Manuel Verdugo”, en G. Santana Henríquez y L. M.

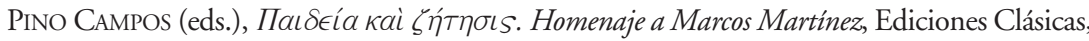
Madrid, pp. 561-570.

Padrón Acosta, S. (1966): Poetas canarios de los siglos XIX y XX, Alianza, Madrid.

Pérez MiniK, D. (2004): Antología de la poesía canaria, CajaCanarias, Santa Cruz de Tenerife.

Sánchez Robayna, A. (1983): Museo Atlántico. Antología de la poesía canaria, editorial Interinsular Canaria, Santa Cruz de Tenerife.

SANTANA, L. (1989): Manuel Verdugo. Estelas y otros poemas, Viceconsejería de cultura y deportes, Gobierno de Canarias, edición número 21 perteneciente a la Biblioteca Básica Canaria, Islas Canarias.

Santana Henríquez, G. (2015): "Agalmatofilia y otras excentricidades amorosas-sexuales de la Grecia Antigua”, en V. Escudero, N. GÓmez, A. NArro (eds.), Omnia vincit Amor. Amor i erotisme a les literatures clàssiques $i$ la sua recepció, Amsterdam, pp. 221-236.

SuÁRez Robaina, J. R. (1992) [En línea]: El mito en "Estelas", de Manuel Verdugo Barlett (18771951), artículo perteneciente a la documentación científica de la ULPGC, Acceda <http://hdl.handle.net/10553/4365> [Consulta: 30/01/2017].

Valbuena Prat, A. (1937): Ha de la poesía canaria. I, Universidad de Barcelona, Seminario de Estudios Hispánicos, Barcelona.

Verdugo Bartlett, M. (1905): Hojas, Madrid.

_ (1909) [En línea]: artículo del periódico titulado El Progreso: Diario Republicano, días 21 y 22 de septiembre, Biblioteca Virtual de Prensa Histórica, Gobierno de España $<$ http://prensahistorica.mcu.es/es/publicaciones/numeros_por_mes.cmd?anyo=1909\&idPublicacion=7295> [Consultado 30/01/2017]

(1922): Estelas, editorial Renacimiento, Madrid. 
- (1931): Burbujas, editorial Wangümert, La Laguna (Tenerife).

- (1944): Autobiografias, Librería Hespérides, Santa Cruz de Tenerife.

_ (1945): Huellas en el páramo, Instituto de Estudios Canarios, La Laguna (Tenerife). 
